\title{
Aspects of Chemical Composition of Exodermal Cell Walls in Roots of Ni-Hyperaccumulating and Non-Hyperaccumulating Genotypes of Senecio coronatus
}

\author{
J. Mesjasz-Przybylowicz ${ }^{1}$, A.D. Barnabas ${ }^{1}$, I. Yousef ${ }^{2}$, P. Dumas², F. Jamme², T.P. Sechogela ${ }^{1}$, W.J. \\ Przybyłowicz ${ }^{1,3}$ \\ 1. Materials Research Department, iThemba LABS, PO Box 722, 7129 Somerset West, South Africa \\ 2. Soleil Synchrotron, BP 48 F91192 Gif sur Yvette Cedex, France \\ 3. AGH University of Science and Technology, Faculty of Physics \& Applied Computer Science, al. A. \\ Mickiewicza 30, 30-059 Krakow, Poland
}

Hyperaccumulation is an unusual plant response to metaliferous soils. Such soils like those derived from ultramafic rocks, have elevated concentrations of heavy metals, mainly $\mathrm{Ni}, \mathrm{Cr}, \mathrm{Zn}$ and $\mathrm{Cd}$. Most plants growing on these soils exclude metals from their shoots as excessive accumulation of heavy metals is toxic to the majority of plants. However, about $2 \%$ of plants growing on metaliferous soils take up and accumulate large quantities of metals in their shoots: a phenomenon known as hyperaccumulation. Senecio coronatus (Thunb) Harv, a widespread South African plant, also occurs on ultramafic outcrops where two genotypes have been identified: a Ni-Hyperaccumulator $(\mathrm{H})$ and a Non-Hyperaccumulator $(\mathrm{NH})$.

In an earlier cytological study of the roots of the genotypes [1], a well-defined Casparian band was identified in radial walls of mature exodermal cells of the $\mathrm{NH}$ following staining with a fluorochrome. In contrast in the $\mathrm{H}$, such a band was not clearly distinguishable. To explore this observation further, chemical composition of exodermal cell walls of the genotypes was investigated as a complementary approach for identification of Casparian bands. These bands, together with other wall modifications such as suberin lamellae, play a crucial role in functioning of the exodermis which serves as a filtration site for the passive movement of ions (including $\mathrm{Ni}$ ) between the soil solution and the stele of roots.

Chemical composition information was obtained using high spatial resolution synchrotron infrared microspectroscopy on thin vibratomed root sections $50 \mathrm{~mm}$ from the root tips, at the SOLEIL Synchrotron Facility in France (SMIS beam line). Most exodermal cells in this part of the roots were still undergoing structural changes, including wall modifications.

Chemical maps were constructed using the integrated absorbance of the $\mathrm{CH}$ stretching region between $3100-2800 \mathrm{~cm}^{-1}$ since suberin, a major component of Casparian bands, is regarded as an insoluble lipid polymer. The maps (Figs.2,5) are confined to the rectangular areas, demarcated by red lines, in the respective visible images of the genotypes (Figs.1,4). An overlay of the chemical images over the visible images (Figs.3,6) shows that the strongest absorbance areas coincide with portions of the cell walls, particularly the radial walls (arrows) in both the NH (Fig.3) and the H (Fig.6). In the exodermal spectrum of the $\mathrm{H}$ these strong absorbance bands appeared at 2923 and $2852 \mathrm{~cm}^{-1}$ which can be assigned to asymmetrical and symmetrical stretching vibration of methylene groups $\left(\mathrm{CH}_{2}\right)$ as they occur in suberin [2], while in the spectrum of the $\mathrm{NH}$ they were at 2919 and $2850 \mathrm{~cm}^{-1}$, also assigned to asymmetrical and symmetrical stretching vibration of suberin methylene groups. The second derivative spectra recorded from exodermal maps of the genotypes display a slight shift in the $\mathrm{CH}_{2}$ stretching vibrational modes. (Fig.7). The $\mathrm{CH}_{2}$ asymmetrical band shifts from 2919 to $2923 \mathrm{~cm}^{-1}$ and the $\mathrm{CH}_{2}$ symmetrical band from 2850 to $2852 \mathrm{~cm}^{-1}$ resulting in a slight upward shift of the $\mathrm{CH}_{2}$ stretching bands in the Ni-Hyperaccumulator. This upward shift in wavelength, according to the literature [3], is 
interpreted as a loss of organization of lipids. It is therefore possible that suberin forming the Casparian bands in radial walls of exodermal cells of the $\mathrm{H}$ is not well organized, probably deposited sparsely, in contrast to the $\mathrm{NH}$ where it forms a more compact layer. This may explain why Casparian bands in the $\mathrm{H}$ are not as distinct (Fig.8, arrow) compared to those in the NH (Fig.9, arrow). There would be a tendency then for more solutes, including $\mathrm{Ni}$, to enter root tissues of the $\mathrm{H}$ thus contributing to $\mathrm{Ni}$ accumulation in the shoots.

\section{References:}

[1] Mesjasz-Przybylowicz J, Barnabas A, Przybylowicz W, Plant Soil 293(2007):61-78.

[2] Zeier J, Schreiber L, Planta 209(1999):537-542.

[3] Moen,B, et al, Canadian Journal of Microbiology 55(2009):714-728.
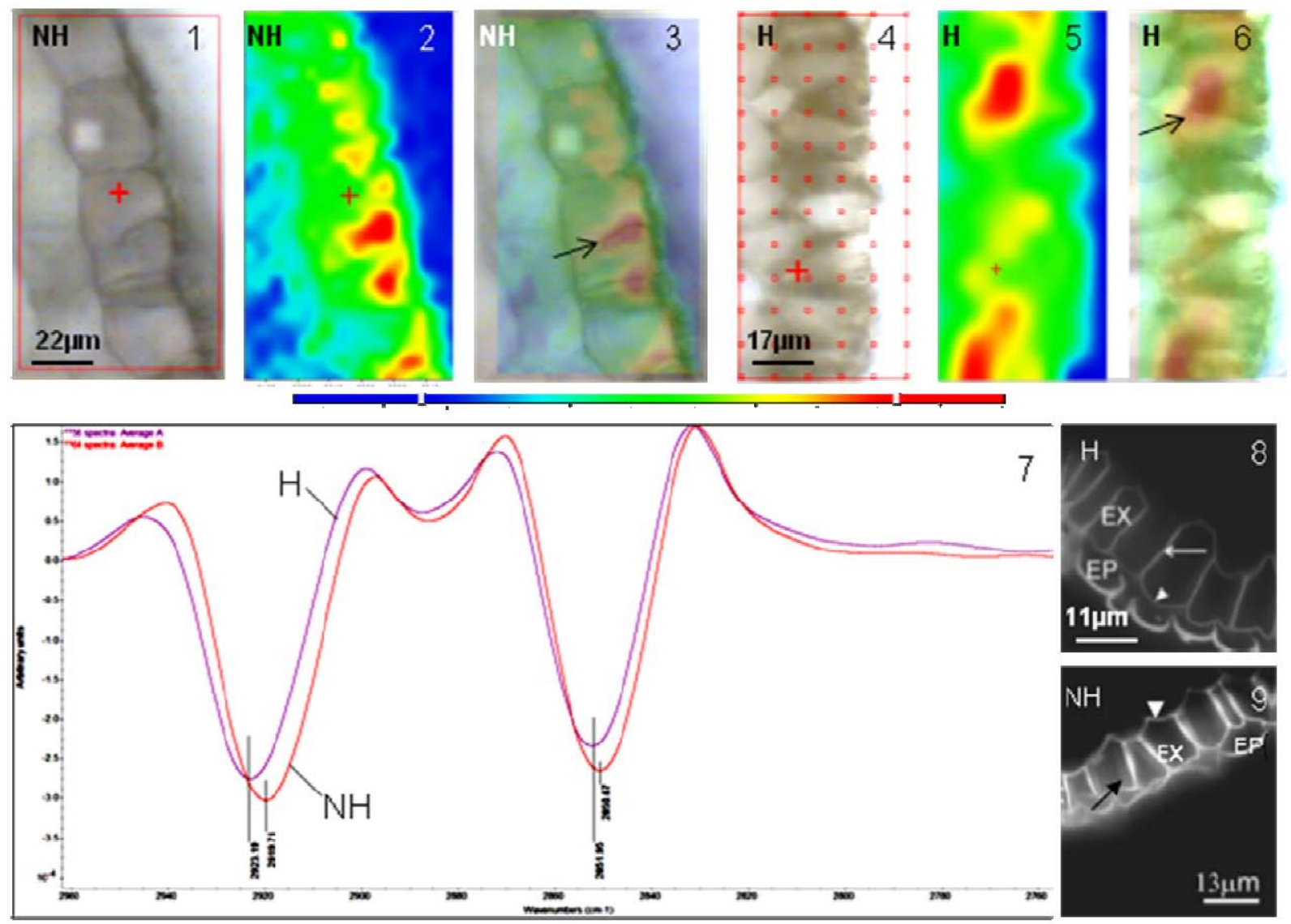

Figs.1-6. Images in visible light $(1,4)$, respective chemical images showing suberin distribution in roots of Senecio coronatus $(2,5)$ and overlay of both $(3,6)$. The warmer colours in Figs.2,3,5,6 (towards the red end of the colour scale) indicate higher absorbance. Fig.7. Average $2 d$ derivative smoothed spectra of $\mathrm{Ni}$ hyperaccumulator ( $\mathrm{H}$, purple) and non-hyperaccumulator ( $\mathrm{NH}$, red). Figs.8,9. Fluorescence micrographs of root exodermis (EX) and epidermis (EP) of hyperaccumulator (Fig.8) and non-hyperaccumulator (Fig.9) stained with berberine hemisulphate for Casparian band detection. Arrowheads: suberin lamellae. 